\title{
Optimizing revascularization strategies in patients with multivessel coronary disease: Impact of intracoronary pressure measurements
}

\author{
Michael Lindstaedt, MD \\ Markus K. Fritz, MD \\ Aydan Yazar, MD \\ Christian Perrey, $\mathrm{MS}^{\mathrm{c}}$ \\ Alfried Germing, MD \\ Peter H. Grewe, MD ${ }^{a}$ \\ Axel M. Laczkovics, MD \\ Andreas Mügge, $M D^{\mathrm{a}}$ \\ Waldemar Bojara, MD ${ }^{a}$
}

\section{From the Medical Clinic II, University Hos- pital Bergmannsheil, Bochum, Germany, ${ }^{\mathrm{a}}$ Division of Cardiothoracic Surgery, Uni- versity Hospital Bergmannsheil, Bochum, Germany, ${ }^{\mathrm{b}}$ and Institute of High Frequency aimed for during the operation. Within diffusely diseased vessels, fractional flow reserve provided an exact segmental resolution of pathologic vessel resistance for optimal graft placement. Significant left main disease was confirmed in 3 of 6 patients and was detected in 3 angiographically unsuspected cases.} Engineering, Ruhr-University-Bochum, Bochum, Germany. ${ }^{\mathrm{c}}$

Received for publication July 10, 2004; revisions received Aug 23, 2004; accepted for publication Aug 27, 2004.

Address for reprints: Michael Lindstaedt, MD, Medizinische Klinik II, Universitätsklinik Bergmannsheil, Ruhr-Universität Bochum, Buerkle-de-la-Camp-Platz 1, 44789 Bochum, Germany (E-mail: michael. lindstaedt@ruhr-uni-bochum.de).

J Thorac Cardiovasc Surg 2005;129: $897-903$

$0022-5223 / \$ 30.00$

Copyright $\odot 2005$ by The American Association for Thoracic Surgery

doi:10.1016/j.jtcvs.2004.08.036

Conclusions: In patients with multivessel disease, coronary pressure-derived fractional flow reserve is a valuable tool to guide clinical decision making and support cardiologists and cardiovascular surgeons in the composition of optimal revascularization strategies.

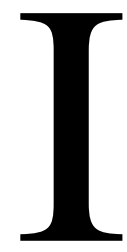
n patients with chest pain and coronary artery disease at angiography, revascularization is indicated if objective evidence of reversible ischemia is present. ${ }^{1,2}$ However, in clinical practice, the decision to revascularize is often based solely on the angiogram even if noninvasive stress testing for inducible ischemia is negative, inconclusive, or not performed at all for multiple reasons. ${ }^{3}$ The interpretation of angiographic information often
Objectives: In patients with multivessel coronary disease, the functional significance of each lesion is often unclear, and preinterventional stress tests may be inconclusive. In this setting, intracoronary pressure measurements may be helpful to define the optimal revascularization strategy.

Methods: Twenty-five consecutive patients (aged $64 \pm 11$ years) with multivessel disease, inconclusive stress tests or not performed stress tests, and an angiographically intermediate coronary artery stenosis in at least 1 major vessel underwent intracoronary pressure measurements. Myocardial fractional flow reserve was measured for the intermediate lesions under the condition of maximum hyperemia induced by intravenous adenosine $\left(140 \mu \mathrm{g} \cdot \mathrm{kg}^{-1} \cdot \mathrm{min}^{-1}\right)$. Revascularization strategies based on angiographic information alone were compared with treatment strategies based on fractional flow reserve results.

Results: The original recommendation of the revascularization procedure of choice (bypass operation or angioplasty) was changed in 9 patients (36\%) on the basis of the results of fractional flow reserve measurements. In 6 more patients, pressure measurements led to a change in the recommended number of anastomoses to be does not correlate with the true morphologic appearance seen by intravascular 
ultrasound or necropsy studies. ${ }^{4,5}$ Most importantly, it frequently does not correlate with the functional significance of a coronary lesion., ${ }^{3,6-9}$

Myocardial fractional flow reserve (FFR) is an invasively determined index of the functional severity of coronary stenoses determined from coronary pressure measurements during cardiac catheterization. ${ }^{10}$ FFR provides information that is specific to the epicardial vascular compartment. It is based on the observation that epicardial atherosclerotic disease significantly obstructs myocardial blood flow only if resistance to flow exceeds the resistance to flow applied by the myocardial microvasculature at maximum vasodilation. If this is not true, then epicardial disease is not the site of significant obstruction to myocardial blood flow, and, thus, neither angioplasty nor operative revascularization could improve blood flow and, consequently, clinical symptoms significantly. FFR is defined as the maximal hyperemic blood flow in the presence of a stenosis divided by the theoretical normal maximal hyperemic blood flow in the same vessel without a stenosis. The normal value of the index is always 1.0. It is calculated as the ratio of mean distal coronary pressure (Pd) divided by mean aortic pressure $(\mathrm{Pa})$ at maximum hyperemia, as follows: $\mathrm{FFR}=$ $\mathrm{Pd} / \mathrm{Pa} .^{11,12}$ This ratio represents the fraction of the normal maximal myocardial flow that can be achieved in the presence of a coronary stenosis. The index is independent of changes in systemic blood pressure, heart rate, or myocardial contractility. It is unaffected by conditions known to increase baseline myocardial flow and is highly reproducible. ${ }^{13-15}$ Because a normal reference vessel is not required, the concept of FFR can also be applied to patients with multivessel disease.

Numerous studies have validated the clinical use of FFR measurements. Pijls and associates ${ }^{11,16}$ and De Bruyne and associates $^{13,17}$ demonstrated that an FFR less than 0.75 correlated closely with inducible ischemia by conventional stress testing. In the study by Pijls and colleagues ${ }^{16}$ sensitivity was $88 \%$, specificity was $100 \%$, and positive and negative predictive values were $100 \%$ and $88 \%$, respectively. The study had a predictive accuracy of $93 \%$. They also showed that revascularization of lesions that reduced FFR to less than 0.75 caused remission of symptoms and normalization of stress test results. Furthermore, a number of studies have reported consistently that deferral of revascularization for stable coronary lesions that do not limit blood flow significantly (ie, FFR $>0.75$ ) leads to favorable clinical outcomes irrespective of angiographic appearance. ${ }^{18-21}$ This was also true for decision making on bypass surgery for equivocal left main coronary artery disease. ${ }^{19,22}$ Because of the extensive and solid data available, intracoronary pressure measurement can certainly be considered the gold standard in the evaluation of the hemodynamic signif- icance of coronary artery lesions. It is applicable even in complex coronary pathologic conditions. ${ }^{23}$

This study was performed in a real-life situation in which explicit proof of ischemia for the supplied myocardium was not available by conventional noninvasive stress testing. It investigated how individual treatment recommendations for coronary revascularization compared in patients with multivessel disease when decisions were based on morphologic information by angiography or on physiologic information by intracoronary pressure measurements.

\section{Patients and Methods Study Population}

The study population consisted of 25 consecutive patients (14 men) with a mean age of $64 \pm 11$ years. Of these, 21 were referred to the cardiology department of our institution for cardiac catheterization because of typical or atypical chest pain. Four patients had been catheterized in other hospitals and were sent to the cardiothoracic surgical department of our institution for coronary bypass surgery. All patients had multivessel disease with coronary artery stenoses of intermediate range by angiography in at least 1 major vessel ( $40 \%$ to $80 \%$ diameter stenosis by quantitative coronary angiography analysis). Conventional stress testing prior to angiography (dobutamine stress echocardiography, thallium scintigraphy, or both) either was inconclusive with respect to the supplied myocardium $(n=14)$ or had not been performed for various reasons $(\mathrm{n}=11)$.

After completion of the coronary angiogram, 2 experienced interventional cardiologists reviewed the angiogram, clinical information, and results of noninvasive diagnostic tests and thereafter gave a consensual definite treatment recommendation. At that time, either intracoronary pressure measurements had not yet been performed or the reviewers were blinded to the results. Pressure measurements were performed by 2 different investigators. A second treatment recommendation was then made by the same former 2 interventional cardiologists on the basis of the additional physiologic information gained from FFR measurements and was compared with the original treatment strategy that was based on angiography alone.

Intracoronary pressure measurements were performed in all vessels with angiographically intermediate lesions. Additional measurements were performed at the investigator's discretion and focused in particular on diffusely diseased vessels, left main stem lesions, and vessels supplying previously infarcted myocardium. Evaluation of the left main stem was part of every measurement in the left coronary artery.

The study was performed in accordance with ethical principles for medical research involving human subjects. ${ }^{24}$ All patients were properly informed before the procedure.

\section{Pressure Measurements and Calculation of FFR}

After insertion of an arterial sheath into the femoral artery, a $6 \mathrm{~F}$ guiding catheter without side holes was advanced into the coronary ostium. The guiding catheter was connected to a fluid-filled pressure transducer zeroed at the midchest level. A 0.014-inch pressure-monitoring guidewire (Pressure Wire 4; Radi Medical Systems, Uppsala, Sweden) was calibrated and then advanced into the 
guiding catheter. The pressure sensor $(3 \mathrm{~cm}$ from the tip of the wire) was positioned at the tip of the guiding catheter to ensure that the pressures recorded by the guiding catheter $(\mathrm{Pa})$ and by the pressure wire $(\mathrm{Pd})$ were identical at that position. Intracoronary isosorbide nitrate was administered at a dose of $0.5 \mathrm{mg}$. The wire was then advanced distal to the segment under investigation and placed in the most distal part of the vessel. Heart rate, $\mathrm{Pa}$, and $\mathrm{Pd}$ were continuously recorded and digitally stored (Radi Analyzer; Radi Medical Systems). Coronary arteriolar vasodilation was induced by the intravenous administration of adenosine (140 $\mu \mathrm{g}$. $\left.\mathrm{kg}^{-1} \cdot \min ^{-1}\right)$ via femoral venous access. FFR was calculated online as the ratio of mean $\mathrm{Pd}$ to mean $\mathrm{Pa}$ during maximal hyperemia. Phasic and mean pressure curves were continuously displayed. At steady-state hyperemia, the pressure wire was slowly pulled back from the most distal to the proximal part of the artery by manual pullback. Upon retraction of the pressure sensor into the guiding catheter, both pressure curves were checked to exclude any drift of the transducer signals during the measurement.

An FFR value less than 0.75 was used as a cutoff to define a functionally significant, ischemia-producing lesion. If a measurement yielded a borderline FFR value between 0.75 and 0.80 , either the hyperemic stimulus was increased to intravenous adenosine $170 \mu \mathrm{g} \cdot \mathrm{kg}^{-1} \cdot \min ^{-1}$ or a repeat measurement was performed with intracoronary papaverine as an alternative hyperemic stimulus to guarantee true maximal hyperemic blood flow and exclude false-negative measurement results. In case of persistent borderline FFR values, the procedure was as follows: in patients with a confirmed indication for bypass surgery due to remaining coronary status, it was recommended to bypass the borderline vessel as well. Otherwise, patients were treated nonsurgically by percutaneous coronary intervention (PCI) and optimized medical treatment with the recommendation of close clinical follow-up after 3 and 6 months.

\section{Results}

Patient characteristics and risk factors for coronary artery disease are shown in Table 1. All intended pressure measurements could be performed successfully. No procedural complications were encountered, and no adverse events were observed that were due to the pharmacologic stimulus for the induction of maximum hyperemia. Table 2 summarizes the data concerning the coronary status obtained in each patient on the basis of angiographic and physiologic evaluation. Furthermore, the consecutive treatment recommendations based on the different methods are shown and compared. The mean number of diseased vessels determined by angiography was 2.64 among all patients. On average, an FFR measurement was performed in 2.16 vessels per patient.

According to the results of intracoronary pressure measurements, the original recommendation for the revascularization procedure of choice was changed in 9 cases $(36 \%)$. Five patients referred to PCI on the basis of angiographic findings were sent to bypass surgery whereas 4 patients intended to undergo operation were treated by means of PCI. Furthermore, in 6 patients with a confirmed indication
TABLE 1. Patient characteristics $(n=25)$

\begin{tabular}{lr}
\hline Variable & Data \\
\hline Male sex & $14(56)$ \\
Age, y (mean \pm SD) & $64 \pm 11$ \\
Cardiovascular risk factors & \\
$\quad$ Hypertension & $17(68)$ \\
Diabetes mellitus & $7(28)$ \\
Hyperlipidemia & $21(84)$ \\
Smoking & $11(44)$ \\
Familial disposition & $4(16)$ \\
Previous PCI & $4(16)$ \\
Previous MI & $6(24)$ \\
CCS class (mean) & 2.8 \\
NYHA class (mean) & 2.6
\end{tabular}

$\mathrm{PCl}$, Percutaneous coronary intervention; $\mathrm{MI}$, myocardial infarction; CCS, Canadian Cardiologic Society; NYHA, New York Heart Association. Data are $\mathrm{n}(\%)$ unless otherwise noted.

for operative revascularization, pressure measurements and pullback maneuvers led to a change in the recommendation for how many anastomoses should be aimed for by the surgeon and where to place them for optimal functional results (see case example $\mathrm{A})$. Left main stem lesions were considered significant in 6 patients on the basis of angiographic evaluation. The hemodynamic significance of these lesions was confirmed in only 3 of these 6 patients, whereas FFR measurement detected significant left main disease (FFR $<0.75)$ in 3 other patients unexpectedly (see case example B). Table 3 summarizes the data of all patients with angiographic and/or physiologic involvement of the left main stem.

\section{Case Example A}

A 43-year-old woman (patient 5 in Table 2) was referred from a regional hospital to the cardiothoracic surgical department of our institution for bypass surgery. The patient presented with typical angina Canadian Cardiovascular Society class III. In accordance with reversible ischemia in the posterior and posterolateral wall seen on thallium scintigraphy, angiography had revealed subtotal ostial stenosis of the right coronary artery (RCA; not shown) and severe ostial stenosis of the left circumflex artery. Left ventricular function was normal. The patient was referred for revascularization of both vessels, whereas the left anterior descending artery (LAD) was not considered significantly diseased. However, the proximal segment of the LAD (Figure 1) seemed equivocal on revision of the angiography before surgery, with an estimated diameter stenosis of approximately $40 \%$. On the request of the surgeon, the patient was investigated again, and an intracoronary pressure measurement was performed in the LAD. FFR was pathologic at 0.73, with a localized pressure decrease along the target lesion (Figure 2). Consequently, the patient received oper- 
TABLE 2. Comparison of angiographic and physiologic results and consecutive treatment recommendations

\begin{tabular}{|c|c|c|c|c|c|c|c|c|c|c|}
\hline $\begin{array}{c}\text { Patient } \\
\text { no. }\end{array}$ & $\begin{array}{c}\text { No. } \\
\text { vessel } \\
\text { disease } \\
\text { by angio }\end{array}$ & $\begin{array}{c}\text { Main stem } \\
\text { involvement } \\
\text { by angio }\end{array}$ & $\begin{array}{c}\text { No. vessels } \\
\text { measured }\end{array}$ & $\begin{array}{c}\text { No. vessel } \\
\text { disease by } \\
\text { FFR } \\
\text { (+ angio) }\end{array}$ & $\begin{array}{c}\text { Main stem } \\
\text { involvement } \\
\text { by FFR }\end{array}$ & $\begin{array}{c}\text { Rx } \\
\text { recomm } \\
\text { by angio }\end{array}$ & $\begin{array}{c}\text { Rx } \\
\text { recomm } \\
\text { by FFR }\end{array}$ & $\begin{array}{c}\text { Change in no. } \\
\text { or loc of } \\
\text { anastomoses }\end{array}$ & $\begin{array}{c}\text { Change of } \\
\text { revasc } \\
\text { procedure }\end{array}$ & $\begin{array}{l}\text { Strategy } \\
\text { change } \\
\text { overall } \\
\end{array}$ \\
\hline 1 & 3 & - & 2 & 3 & - & OP & OP & No & No & No \\
\hline 2 & 3 & - & 2 & 1 & - & OP & OP & No & No & No \\
\hline 3 & 2 & - & 2 & 3 & Yes & $\mathrm{PCl}$ & OP & - & Yes & Yes \\
\hline 4 & 3 & Yes & 3 & 1 & No & OP & $\mathrm{PCl}$ & - & Yes & Yes \\
\hline 5 & 2 & - & 2 & 3 & - & OP & OP & Yes & No & Yes \\
\hline 6 & 3 & Yes & 2 & 3 & Yes & $\mathrm{OP}$ & OP & No & No & No \\
\hline 7 & 3 & - & 1 & 3 & - & $\mathrm{OP}$ & OP & No & No & No \\
\hline 8 & 2 & - & 1 & 2 & - & $\mathrm{OP}$ & OP & No & No & No \\
\hline 9 & 3 & - & 4 & 3 & - & $\mathrm{OP}$ & OP & Yes & No & Yes \\
\hline 10 & 2 & - & 3 & 3 & Yes & $\mathrm{PCl}$ & $\mathrm{OP}$ & - & Yes & Yes \\
\hline 11 & 3 & - & 2 & 3 & - & $\mathrm{OP}$ & $\mathrm{OP}$ & Yes & No & Yes \\
\hline 12 & 3 & - & 1 & 3 & - & $\mathrm{OP}$ & $\mathrm{OP}$ & No & No & No \\
\hline 13 & 3 & Yes & 2 & 1 & No & $\mathrm{OP}$ & $\mathrm{PCl}$ & - & Yes & Yes \\
\hline 14 & 2 & - & 3 & 3 & - & $\mathrm{PCl}$ & $\mathrm{OP}$ & - & Yes & Yes \\
\hline 15 & 3 & Yes & 4 & 3 & Yes & $\mathrm{OP}$ & $\mathrm{OP}$ & Yes & No & Yes \\
\hline 16 & 3 & - & 1 & 3 & - & $\mathrm{OP}$ & $\mathrm{OP}$ & No & No & No \\
\hline 17 & 3 & - & 2 & 3 & - & $\mathrm{OP}$ & $\mathrm{OP}$ & No & No & No \\
\hline 18 & 3 & - & 3 & 1 & - & $\mathrm{OP}$ & $\mathrm{PCl}$ & - & Yes & Yes \\
\hline 19 & 3 & - & 1 & 3 & - & $\mathrm{OP}$ & $\mathrm{OP}$ & No & No & No \\
\hline 20 & 2 & - & 3 & 3 & - & $\mathrm{PCl}$ & $\mathrm{OP}$ & - & Yes & Yes \\
\hline 21 & 2 & - & 1 & 3 & Yes & $\mathrm{PCl}$ & $\mathrm{OP}$ & - & Yes & Yes \\
\hline 22 & 3 & - & 2 & 3 & - & $\mathrm{OP}$ & $\mathrm{OP}$ & Yes & No & Yes \\
\hline 23 & 3 & Yes & 3 & 3 & Yes & $\mathrm{OP}$ & OP & No & No & No \\
\hline 24 & 2 & - & 2 & 3 & - & $\mathrm{OP}$ & $\mathrm{OP}$ & Yes & No & Yes \\
\hline 25 & 3 & Yes & 2 & 1 & No & $\mathrm{OP}$ & $\mathrm{PCl}$ & - & Yes & Yes \\
\hline
\end{tabular}

Angio, Angiography; FFR, myocardial fractional flow reserve; $R x$, treatment; recomm, recommendation; loc, location; revasc, revascularization; $O P$, operation; $\mathrm{PCl}$, percutaneous coronary intervention.

TABLE 3. Patients with left main stem involvement by angiography, FFR, or both $(\mathrm{n}=9)$

\begin{tabular}{ccccc}
\hline $\begin{array}{c}\text { Patient } \\
\text { no. }\end{array}$ & $\begin{array}{c}\text { Main stem } \\
\text { involvement } \\
\text { by angio }\end{array}$ & $\begin{array}{c}\text { \% Stenosis } \\
\text { by angio } \\
\text { (OCA) }\end{array}$ & $\begin{array}{c}\text { Main stem } \\
\text { involvement } \\
\text { by FFR }\end{array}$ & FFR \\
\hline 3 & - & 27 & Yes & 0.67 \\
4 & Yes & 70 & - & 1.00 \\
6 & Yes & 50 & Yes & 0.73 \\
10 & - & 33 & Yes & 0.68 \\
13 & Yes & 74 & - & 0.96 \\
15 & Yes & 65 & Yes & 0.60 \\
21 & - & 24 & Yes & 0.73 \\
23 & Yes & 75 & Yes & 0.73 \\
25 & Yes & 63 & - & 0.89 \\
\hline
\end{tabular}

Angio, Angiography; FFR, Myocardial fractional flow reserve; $Q C A$, quantitative coronary angiography.

ative revascularization of all 3 main coronary arteries. It is likely that otherwise the therapeutic intention to rid this young patient of anginal symptoms on physical exertion would not have been achieved after surgery.
Case Example B

A 73-year-old man (patient 21 in Table 2) presented with progressive dyspnea New York Heart Association class III-IV but without typical angina. Scintigraphy indicated a myocardial defect with adjacent reversible ischemia in the posterior wall. He had a history of posterior myocardial infarctions in 1988 and 1993. A PCI of the RCA was performed in 1993, followed by rotablation of the same vessel 1 year thereafter. The angiogram showed akinesia of the posterior wall but only moderately impaired left ventricular function. Severe ostial stenosis of the RCA was seen (not shown), and angioplasty with a drugeluting stent was considered. No circumscript lesions were found in the left coronary artery except for an intermediate stenosis in the large intermediate branch. Except for minor sclerotic disease, no significant stenosis was seen in the left main stem by unanimous consensus of the reviewing cardiologists. However, the morphology of the distal left main stem was difficult to evaluate (Figures 3 and 4). The pressure measurement performed to evaluate the lesion of the intermediate branch revealed 


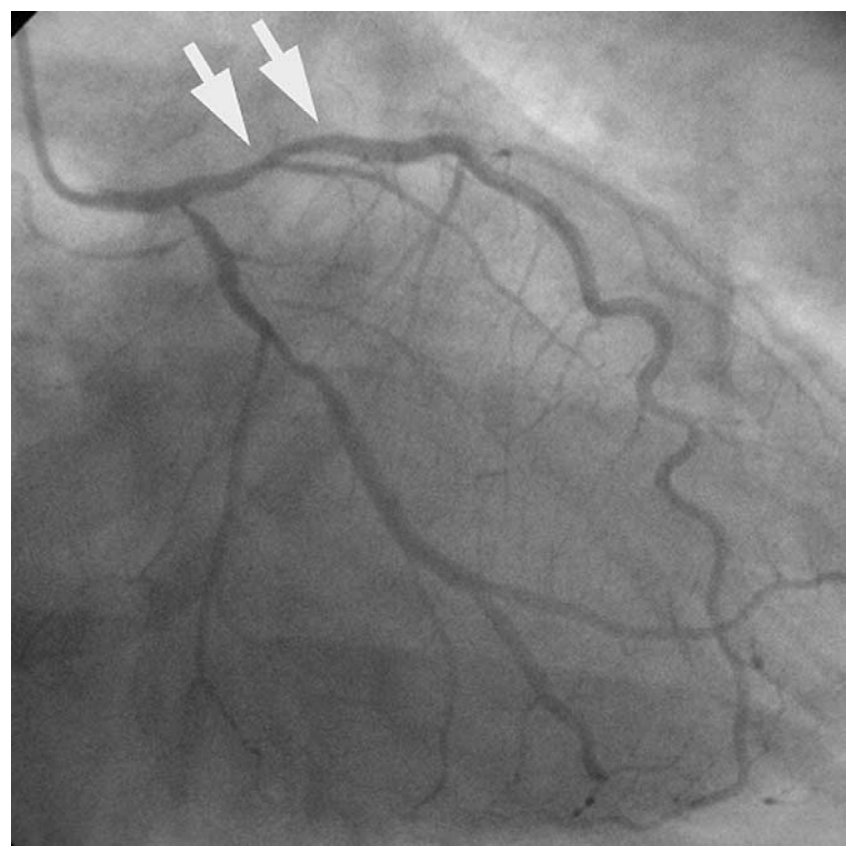

Figure 1. Case A. Left coronary artery in a right anterior oblique projection. Arrows indicate a proximal LAD segment with an equivocal lesion.

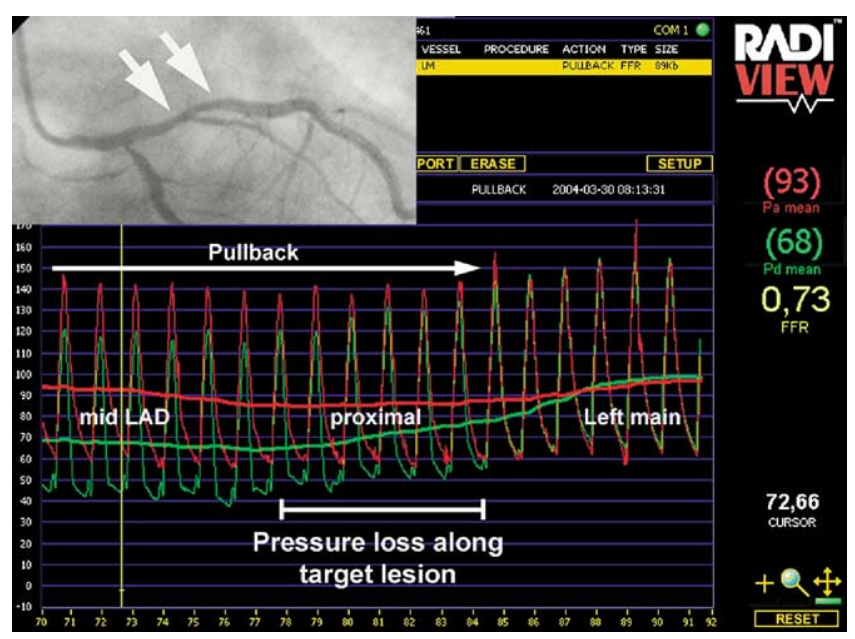

Figure 2. Case $A$. Recording of pressure measurement in the LAD ( $\mathrm{Pa}$ in red; $\mathrm{Pd}$ in green). Both phasic and mean pressure curves are shown. From left to right: pullback pressure curve from the mid LAD across the proximal lesion into the left main artery. The FFR is 0.73 in the mid LAD (value measured at the position of the yellow line on the left of the display); normalization of the pressure curves occurred proximal to the lesion.

a localized pressure drop in the distal left main stem upon pullback of the pressure wire. A repeat measurement in the LAD confirmed a functionally severe stenosis (FFR 0.61) with a pressure drop in the exact same position

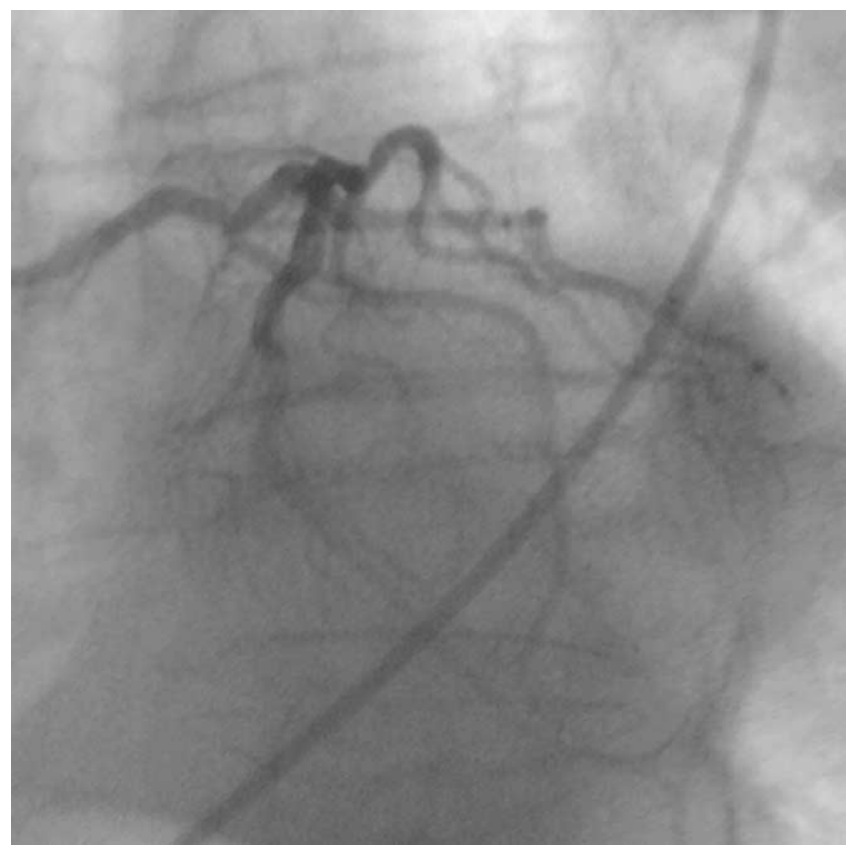

Figure 3. Case B. Left coronary artery in an anteroposterior cranial projection.

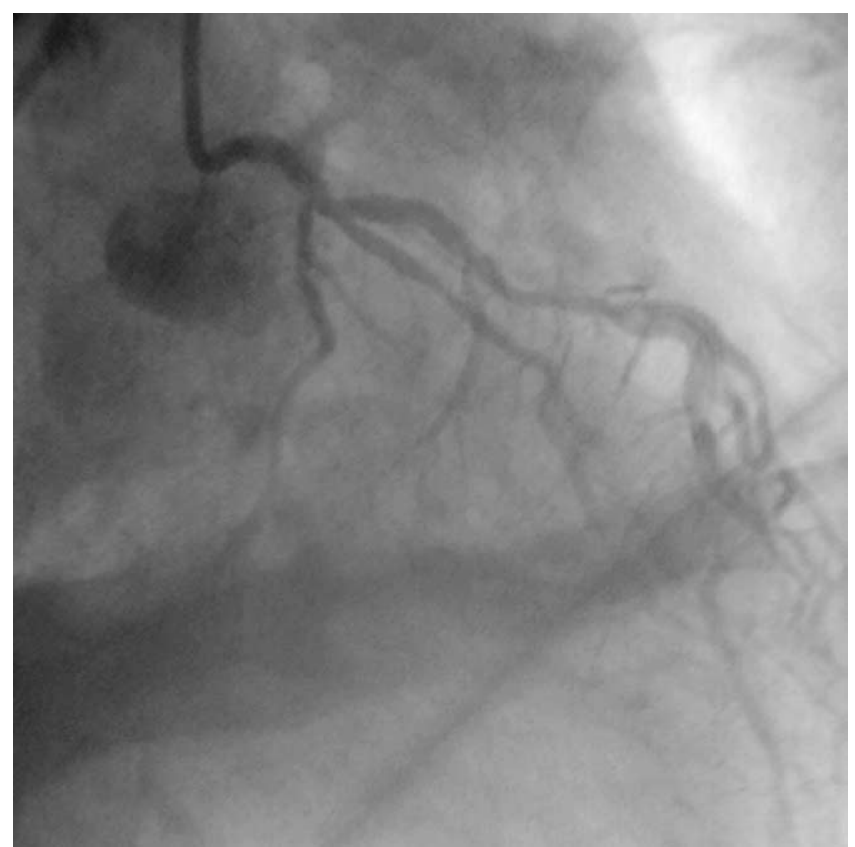

Figure 4. Case B. Left coronary artery in a right anterior oblique projection.

(Figure 5). Angioplasty therefore was deferred, and the patient was sent to bypass surgery for complete revascularization because of a symptomatic and a prognostic indication. 


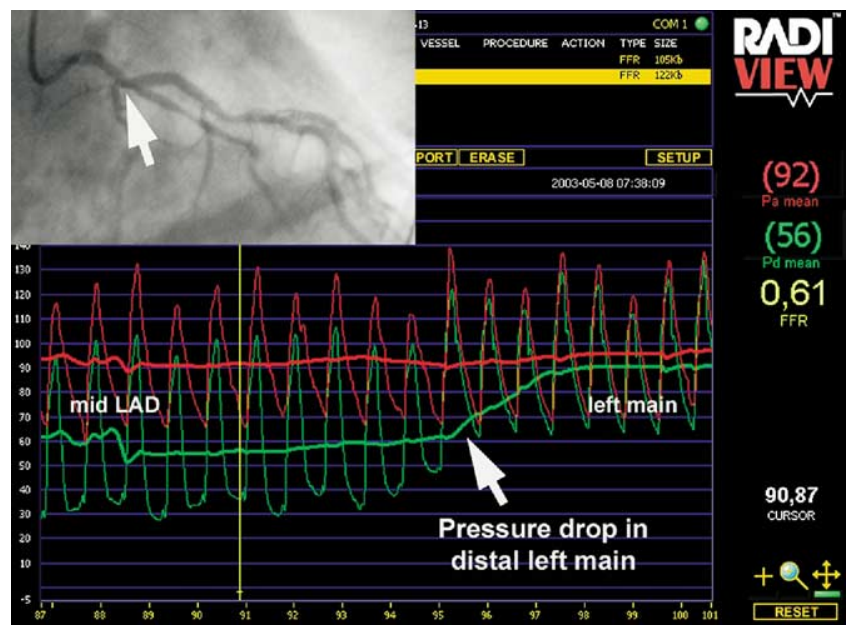

Figure 5. Case B. Recording of pressure measurement in the LAD ( $\mathrm{Pa}$ in red; $\mathrm{Pd}$ in green). From left to right: pullback pressure curve from the mid LAD into the left main artery. The FFR is 0.61 in the mid LAD (value measured at the position of the yellow line on the left of the display). A sudden pressure drop in the distal left main stem is indicated by arrows.

\section{Discussion}

This small prospective study on 25 patients with multivessel disease indicates that treatment recommendations for the revascularization procedure of choice based on angiographic information frequently are not optimal and in some cases are inadequate. The study population consisted of patients without objective proof of ischemia and with at least 1 intermediate stenosis by angiography in 1 of the native target vessels. In this real-life situation, intracoronary pressure measurements were performed to obtain the missing physiologic information on reversible ischemia strongly requested in the forefront of any revascularization procedure. ${ }^{1}$ On the basis of the FFR measurement, the original treatment recommendation had to be changed in $36 \%$ of cases with respect to the revascularization procedure of choice (coronary artery bypass grafting vs PCI). In another $24 \%$ of cases, the pressure measurement optimized the operative strategy (see case example A). Our results are in line with observations made by Brueren and colleagues, ${ }^{8}$ who assessed the accuracy of eyeball estimation of equivocal coronary stenoses by experienced cardiologists when taking FFR as the gold standard. Most study patients had 1 -vessel disease located in the LAD. In their study, visual lesion assessment would have resulted in a wrong decision in $30.7 \%$ of cases. In detail, unnecessary PCI would have been performed in $11.5 \%$ of cases, and indicated PCI would have been withheld in $19.2 \%$ of cases. Our study is the first to compare patients with multivessel disease, and, thus, it is not surprising that the discrepancy observed was even higher.
It is widely known that angiographic visualization of the coronary arteries is a relatively poor representation of coronary anatomy and has limited value for making decisions with regard to revascularization. ${ }^{6}$ Furthermore, there is substantial intraobserver and interobserver variability. ${ }^{25}$ Assessment of stenosis severity by quantitative coronary angiography is equally insufficient and neither is a functional parameter nor is routinely performed. Consequently, the interpretation of angiographic information should be based on functional assessment of ischemia. Conventional stress tests such as bicycle ergometry, stress echocardiography, and myocardial scintigraphy all have inherent limitations that apply in particular in patients with multivessel disease. $^{26}$ Not surprisingly, proof of reversible ischemia is frequently lacking or inconclusive in routine clinical practice. $^{3}$

None of the aforementioned techniques has a sensitivity or specificity comparable with the measurement of FFR. ${ }^{27}$ Furthermore, intracoronary pressure measurement yields a segmental and spatial resolution of the extent of epicardial coronary artery disease that is unsurpassed by any other technique. FFR not only reliably identifies a culprit vessel, but also identifies the exact location of obstruction to blood flow by online analysis of pressure curves during pullback of the pressure wire. ${ }^{28}$ In 6 of our patients, the pullback curves provided information for optimizing the operative strategy with respect to the number and location of anastomoses aimed for during surgery.

The value of FFR measurement is particularly striking in some cases of equivocal left main stem disease. The presence of left main coronary artery disease may have serious implications, and it is often decisive in the choice of surgical versus interventional treatment. ${ }^{29}$ In our small patient population, 3 of 6 left main stem lesions were overestimated in their functional severity by visual assessment, and patients did not undergo surgery. However, equally striking was the detection of left main stem disease in 3 cases for which no significant involvement of the left main stem was suspected (see case example B). These patients underwent surgery instead of angioplasty. Our findings suggest that the patient subset investigated should be approached with a high degree of clinical suspicion concerning left main artery involvement. The feasibility and safety of an FFR-guided approach in decision making about bypass surgery for equivocal left main coronary artery disease have been proven by Bech and coworkers. ${ }^{22}$ In the 54 patients they studied, medical instead of surgical treatment was used in 24 patients with FFR greater than or equal to 0.75 , whereas bypass surgery was performed in the remaining patients, who had FFR values less than 0.75 . The survival of the patients in the medical treatment and surgical groups was $100 \%$ and $97 \%$, respectively. Mean follow-up was 29 months. The event-free survival was $76 \%$ in the medical treatment group and $83 \%$ 
in the surgical group. No death or acute myocardial infarction occurred in any of the patients in whom angioplasty was deferred.

We conclude that measurement of FFR is a valuable tool for the development of individually tailored strategies in revascularization management. When there is doubt about the need for revascularization or the procedure of choice, coronary pressure-derived FFR can be used as a reliable and lesion-specific index to guide clinical decision making. This may apply in particular to patients who present with multivessel disease and thus may help both cardiologists and cardiothoracic surgeons to cooperate in the composition of optimal revascularization strategies.

\section{References}

1. Guidelines for percutaneous transluminal coronary angioplasty. A report of the American College of Cardiology/American Heart Association Task Force on Assessment of Diagnostic and Therapeutic Cardiovascular Procedures (Committee on Percutaneous Transluminal Coronary Angioplasty). J Am Coll Cardiol. 1993;22:2033-54.

2. Management of stable angina pectoris. Recommendations of the Task Force of the European Society of Cardiology. Eur Heart J. 1997;18: 394-413.

3. Topol EJ, Ellis SG, Cosgrove DM, Bates ER, Muller DW, Schork NJ, et al. Analysis of coronary angioplasty practice in the United States with an insurance-claims data base. Circulation 1993;87:1489-97.

4. Klocke FJ. Cognition in the era of technology: "seeing the shades of gray." J Am Coll Cardiol. 1990;16:763-9.

5. Nissen SE, Gurley JC, Grines CL, Booth DC, McClure R, Berk M, et al. Intravascular ultrasound assessment of lumen size and wall morphology in normal subjects and patients with coronary artery disease. Circulation. 1991;84:1087-99.

6. Topol EJ, Nissen SE. Our preoccupation with coronary luminology. The dissociation between clinical and angiographic findings in ischemic heart disease. Circulation. 1995;92:2333-42.

7. Wilson RF. Looks aren't everything. FFR B4 U PTCA. Circulation. 2001;103:2873-5.

8. Brueren BR, ten Berg JM, Suttorp MJ, Bal ET, Ernst JM, Mast EG, et al. How good are experienced cardiologists at predicting the hemodynamic severity of coronary stenoses when taking fractional flow reserve as the gold standard? Int J Cardiovasc Imaging. 2002;18:73-6.

9. White CW, Wright CB, Doty DB, Hiratza LF, Eastham CL, Harrison DG, et al. Does visual interpretation of the coronary arteriogram predict the physiologic importance of a coronary stenosis? $N$ Engl J Med. 1984;310:819-24.

10. Pijls NH, Van Gelder B, Van der Voort P, Peels K, Bracke FA, Bonnier HJ, et al. Fractional flow reserve. A useful index to evaluate the influence of an epicardial coronary stenosis on myocardial blood flow. Circulation. 1995;92:3183-93.

11. Pijls NH, Aengevaeren WR, Uijen GJ, Hoevelaken A, Pijnenburg T, van Leeuwen $\mathrm{K}$, et al. Concept of maximal flow ratio for immediate evaluation of percutaneous transluminal coronary angioplasty result by videodensitometry. Circulation. 1991;83:854-65.

12. Pijls NH, van Son JA, Kirkeeide RL, De Bruyne B, Gould KL. Experimental basis of determining maximum coronary, myocardial, and collateral blood flow by pressure measurements for assessing functional stenosis severity before and after percutaneous transluminal coronary angioplasty. Circulation. 1993;87:1354-67.
13. De Bruyne B, Sys SU, Heyndrickx GR. Percutaneous transluminal coronary angioplasty catheters versus fluid-filled pressure monitoring guidewires for coronary pressure measurements and correlation with quantitative coronary angiography. Am J Cardiol. 1993;72:1101-6.

14. De Bruyne B, Paulus WJ, Pijls NH. Rationale and application of coronary transstenotic pressure gradient measurements. Cathet Cardiovasc Diagn. 1994;33:250-61.

15. De Bruyne B, Bartunek J, Sys SU, Pijls NH, Heyndrickx GR, Wijns W. Simultaneous coronary pressure and flow velocity measurements in humans. Feasibility, reproducibility, and hemodynamic dependence of coronary flow velocity reserve, hyperemic flow versus pressure slope index, and fractional flow reserve. Circulation. 1996;94:1842-9.

16. Pijls NH, De Bruyne B, Peels K, Van Der Voort PH, Bonnier HJ, Bartunek JKJ, et al. Measurement of fractional flow reserve to assess the functional severity of coronary-artery stenoses. $N$ Engl J Med. 1996;334:1703-8.

17. De Bruyne B, Bartunek J, Sys SU, Heyndrickx GR. Relation between myocardial fractional flow reserve calculated from coronary pressure measurements and exercise-induced myocardial ischemia. Circulation. 1995;92:39-46.

18. Kern MJ, Donohue TJ, Aguirre FV, Bach RG, Caracciolo EA, Wolford $\mathrm{T}$, et al. Clinical outcome of deferring angioplasty in patients with normal translesional pressure-flow velocity measurements. $J$ Am Coll Cardiol. 1995;25:178-87.

19. Bech GJ, De Bruyne B, Bonnier HJ, Bartunek J, Wijns W, Peels K, et al. Long-term follow-up after deferral of percutaneous transluminal coronary angioplasty of intermediate stenosis on the basis of coronary pressure measurement. J Am Coll Cardiol. 1998;31:841-7.

20. Bech GJ, De Bruyne B, Pijls NH, de Muinck ED, Hoorntje JC, Escaned J, et al. Fractional flow reserve to determine the appropriateness of angioplasty in moderate coronary stenosis: a randomized trial. Circulation. 2001;103:2928-34.

21. Chamuleau SA, Meuwissen M, Koch KT, Eck-Smit BL, Tio RA, Tijssen JG, et al. Usefulness of fractional flow reserve for risk stratification of patients with multivessel coronary artery disease and an intermediate stenosis. Am J Cardiol. 2002;89:377-80.

22. Bech GJ, Droste H, Pijls NH, De Bruyne B, Bonnier JJ, Michels HR, et al. Value of fractional flow reserve in making decisions about bypass surgery for equivocal left main coronary artery disease. Heart. 2001;86:547-52.

23. Hau WK. Fractional flow reserve and complex coronary pathologic conditions. Eur Heart J. 2004;25:723-7.

24. World Medical Association Declaration of Helsinki: ethical principles for medical research involving human subjects. JAMA. 2000;284: 3043-5.

25. Zir LM, Miller SW, Dinsmore RE, Gilbert JP, Harthorne JW. Interobserver variability in coronary angiography. Circulation. 1976;53: 627-32.

26. Lee TH, Boucher CA. Clinical practice. Noninvasive tests in patients with stable coronary artery disease. $N$ Engl J Med. 2001;344:1840-5.

27. Scanlon PJ, Faxon DP, Audet AM, Carabello B, Dehmer GJ, Eagle $\mathrm{KA}$, et al. ACC/AHA guidelines for coronary angiography. A report of the American College of Cardiology/American Heart Association Task Force on practice guidelines (Committee on Coronary Angiography). Developed in collaboration with the Society for Cardiac Angiography and Interventions. J Am Coll Cardiol. 1999;33:1756-824.

28. De Bruyne B, Hersbach F, Pijls NH, Bartunek J, Bech JW, Heyndrickx GR, et al. Abnormal epicardial coronary resistance in patients with diffuse atherosclerosis but "normal" coronary angiography. Circulation. 2001; 104:2401-6.

29. Caracciolo EA, Davis KB, Sopko G, Kaiser GC, Corley SD, Schaff H, et al. Comparison of surgical and medical group survival in patients with left main coronary artery disease. Long-term CASS experience. Circulation. 1995;91:2325-34. 